\title{
Estimating the Recreational Value of the Abdanan Black Twin Lake: A Contingent Valuation Approach
}

\author{
Ali Sayehmiri \\ Assistant Professor of Economics, Faculty of Social Science, Ilam University, Ilam, Iran \\ a.sayehmiri@ilam.ac.ir \\ Atefeh Haydarvand \\ Atefeh.heidarvand@yahoo.com \\ M.A student of Economics, Faculty of Social Science, Ilam University, Ilam, Iran
}

\begin{abstract}
As one of the unique destinations in Iran, Abdanan Black Twin Lake attracts many tourists yearly. Among striking features is the presence of minerals, boiling springs and its beautiful landscape. The human beings are willing to spend money for such natural resources. Economic valuation can be interfered constructively and positively in improving environmental policies. So, quantifying these benefits is of the utmost importance. The paper mainly estimated the tourists' willingness to pay and their recreational value using contingent valuation method. Random sampling was conducted on 384 people using two-dimensional double-choice questionnaire in spring 2019. In the Twin Lake Recreational Value Questionnaire, the main questions were devoted to the visitors' willingness to pay, with three bids of $0.07 \$, 0.14 \$$ and $0.22 \$$. Among 384 respondents, $304(79 \%)$ were willing to pay for recreational use of the lake, and 80 respondents $(21 \%)$ were not. Likelihood, the model's parameters were estimated. The findings indicated the average tourists' willingness to pay for recreational value was estimated $0.09 \$$ per visit and recreational value of this lake for each household was estimated $0.40 \$$. The findings revealed the effect of education, household income, household size and tourists' willingness to pay was significant.
\end{abstract}

Keywords: Black Twin Lake of Abdanan, Recreational Value, contingent Valuation, Willingness to Pay, Logit Model

\section{Introduction}

Human beings need to be in touch with nature for many reasons and, therefore, he is bound to preserve it. Today, tourism is considered an appropriate way to spend leisure time. Since being viewed to reduce the impact of the increasing stresses of urban and industrial life, it has attracted more attention than ever. The expansion of economic activities, population growth, rising living standards and rising standards of living, air pollution in major cities, noise pollution and other environmental pollutants have increased the demand for natural environments and the need for tourism. It has come to make urban people more in need of nature and natural attractions day by day. Potential recreational income and the use of nature forest areas for leisure and recreation are viewed as direct values, but ecological services are considered indirect values such as the ability of these areas in absorbing carbon and changing climate. Existential value is the intrinsic value of a resource that people only consider the existence of that resource and environmental activities, even if they never see or use it. (Shaabanzadeh et al., 2014: 2). At the moment, sustainable development, environmental protection and improvement, proper utilization of natural resources and multilateral recreational, educational and research use of natural environmental conditions are issues influencing economic growth and social welfare worldwide (Amirnejad \& Rafiei, 2009: 2). 
Economic valuation of natural ecosystems expresses the monetary value of the goods and services an ecosystem can provide. Some of these goods and services are traded as marketable (such as forest trees), but others are recognized as non-marketable and, although valuable, but not capable. Their monetary valuation is often overlooked in environmental decision making (Yavari \& Bazardeh, 2017: 3).

The main purpose of economic evaluation of ecosystems is supposed to provide information that helps decision makers to make efficient use of available resources to maximize community improvement and prosperity. Resource, whatever is, can influence human conditions; therefore, the term "resource" involves environmental and natural resources from an economic viewpoint. In fact, economic valuation of resources helps planners and executive, social and economic managers to plan, conserve and exploitation of natural resources sustainably through revealing quantification value of functions, services and goods of ecosystems (Ghorbani, 2008: 110). Therefore, given the increasing demand of recreation centers and resorts, it is necessarily recommended to investigate thoroughly people's needs, and introduce socio-economic analysis, as well as anticipate recreational and leisure needs of individuals in order to provide necessary facilities and facilities (AsafuAdjaye, 2005:87). Various studies have been conducted in and around the country to measure the recreational value of public places and tourist attractions, some of them are briefly mentioned here.

In a study conducted on the recreational value of Mellat Park in Ilam City and visitors' willingness to pay (WTP) for this park using the contingent valuation method (CVM) with a double choice questionnaire, Teimornejad and et al. (2019) estimated that the average willingness to pay for each The 5-person household was worth 45,000 Rials (0.33\$) and the average visitors' willingness to pay for the amusement value of the park was 8925 Rials $(0.66 \$)$ per visit.

Mahdavi et al. (2017), in his study, dealt with estimating the recreational value of Choghsabz forest park in Ilam city using the contingent valuation method. Findings indicated that the average willingness to pay for visiting this park cost 1396969 Rials (103\$) and the average willingness to pay per household was worth 390908.2 Rials (29\$).

Seyed Salehi et al. (1986), in a study, estimated the economic benefits of Shiraz Azadi Park using a two-dimensional contingent valuation method. Based upon the study, visitors were willing to pay 4390 Rials $(0.32 \$)$ for one day to use and the total benefit of the park was about 14 billion Rials (10371\$) annually.

Moslemi and et al. (2016) rated the economic value of the tourism area of Roudbar Qasran using the contingent valuation method. The results of their analysis indicated that the average tourists' willingness to pay per household was 7100 Rials $(0.05 \$)$ and with regards to this value, the average recreational value of services in this region was estimated 3550 million Rials (26300\$). Karami et al. (2016), in a study, estimated the recreational value of the Najwan Forest Park using the contingent valuation method. The average visitors' willingness to pay for recreational use of the park was estimated 1137 Rials (0.08\$). Mousavi (2015), in an article, dealt with estimating the economic-recreational valuation of waterfall and recreational area of Khafar and determining the factors influencing the willingness to pay using CVM contingent valuation method. The average willingness to pay cost 275878 Rials 
(2\$) and the Eco touristic value of Khafar Waterfall and Amusement Park in this study was estimated 510701000 Rials (3782\$) annually.

Rajabi and Mousavi (2014) investigated the economic valuation of Nakhsh-e-Jahan square in Isfahan using the visitors' willingness to pay to visit and preserve its buildings. With regards to this study, the individuals' willingness to pay and the number of domestic visitors from the complex of buildings of Naghsh-e-Jahan Square, tourism and conservation valuation were estimated over 12630 and 465920 million Rials ( $93555 \$$ and $3451259 \$$ ), respectively. Rahli et al (2013), in a study, evaluated the recreational value and examined the factors affecting tourists' willingness to pay for the Tabriz Ruined Mill Cascade using contingent valuation method. The average willingness to pay among the visitors was 4,000 Rials $(0.02 \$)$ and the annual recreational value of the attraction was estimated 380 million Rials (2814\$). Rathnayake (2016) referred to his study entitled Tourism Management Perspective on the Minneriya National Park, located among the elephant conservation areas in Sri Lanka, and averaged US \$ 1.30 (17200 Rs. Sri Lanka) as a WTP payment per each domestic visitor. Nandajiri (2015) utilized a contingent valuation method aimed to estimate the willingness of visitors to pay for recreational use of the lake's services and facilities in India in a study on the economic value of Lake Pi Kola. According to the results obtained through open-ended questionnaire, the average amount of willingness to pay for creating additional facilities in the lake was $36.75 \mathrm{Rs}$ and the average willingness to pay for improving lake water quality was 40.13 Rs. In a study, Halkos and Matsiori (2014) examined the social attitudes and people's willingness to pay for water resources protection using the contingent valuation method. The research was conducted through double-blind sampling and face-to-face interviews. The average willingness to pay was estimated $33.78 €$.

In an article using the contingent valuation method, Jianjun et al. (2013) evaluated the people's willingness to pay for protection of cultivated land in Wenling city, China, and used stratified random sampling method to select the sample. The results of this study showed that the average willingness of people to pay for the protection of cultivated land in this city is 26.99 yuan (\$3.96) per household for 10 years per month and the total benefits of protecting cultivated land in Wenneling, was estimated at about 24 million Yuan (\$ 3.5 million). In a study using two contingent valuation methods and travel costs, Voke et al. (2013) estimated the recreational value of a coastal area in England. The results of their study showed that the average value obtained per person based on the two methods to travel cost and contingent valuation is about $148 £$ and $6.7 £$, respectively. The current paper aimed to determine the recreational value of Abdanan Black Twin Lake with regards to natural resource valuation through using contingent valuation method.

\section{Methodology}

The methodology of this study was descriptive-analytical through an applied type. The data gathering method was a survey with questionnaire distribution. The contingent valuation method and Logit model have been used to estimate the recreational value of the lake and the visitors' willingness to pay rate. The statistical population participated in this study is lake visitors. After setting up the two-dimensional dual questionnaire through using simple random sampling approach, Questionnaires were completed. This procedure requires identifying and selecting one suggestion more than the initial. The suggestion depends more 
on "yes or no" response or the participant's response to the initial proposal (Marta, Pedroso et al.; 2007: 388). The sample size was calculated 384 individuals using Cochran formula.

The economic valuation process of the Black Twin Lakes Lake through using the contingent valuation method is as follows: In this method the dependent variable for the valuation of Black Twin Lake is the probability of accepting a bid for recreational use of the lake. This variable is estimated in response to the question, "Is every visitor willing to pay for the recreational use of this lake as an entrance fee?" An individual will be in a position to pay for environmental goods whose utility is greater when he uses or protects the goods in question and pays for them as entrance or taxes than when he does not use and protect them (Park and Loomis, 1996: 150). Mathematically:

$$
\mathrm{u}\left(1, \operatorname{Inc}-\mathrm{BID}_{,} \mathrm{s}\right)+\varepsilon_{1} \geq \mathrm{u}(0, \operatorname{Inc}, \mathrm{s})+\varepsilon_{0}
$$

Where $\mathbf{U}$ stands for an individual indirect utility, Inc is an individual income, BID is a bid price, and $\mathbf{S}$ stands for other individual socio-economic characteristics influenced by his or her taste. $\varepsilon_{0}$ are random variables with zero mean and normal distribution of disruptive $\varepsilon_{1} 9$ components. And, u (0) refers to a situation where one does not pay for the use or protection of the lake, and $u(1)$ relates to other things. Consequently, the utility difference $(\Delta U)$ is defined as follows:

$$
\Delta U=(1, \text { Income }- \text { Bid }, S)-U(0, \text { Income }, S)+\left(\varepsilon_{1}-\varepsilon_{0}\right)
$$

If $\Delta U$ is greater than zero, it means that the respondent will maximize his / her utility by saying "yes" and agreeing to pay for the use of the Black Twin Lake. In other words, accepting one to pay is a function of Inc, BID, and S, Therefore, the dependent variable for recreational valuation is qualitative and holds only zero and one values. In such cases, regression models with qualitative variables are suitable models. Generally, linear probability, Logit, Probit, and Tobit models are used to investigate regressions that have binary dependent variables (Helper and Market, 1396: 141).

Based on the logit model used in this paper, the probability (pi) of an offer being accepted by an individual is shown as follows. (Silk, 1378: 117):

$$
\text { (3) } P_{i}=F_{\eta}(\Delta U)=\frac{1}{1+\exp (-\Delta U)}=\frac{1}{1+\exp \{-(\alpha-\beta B i d+\gamma I n c+\theta S)\}}
$$

Where,

$F_{\eta}(\Delta U)$ refers to function of the standard logistic cumulative distribution that involves some socioeconomic variables in this study. $B, \gamma$ and $\theta$ are estimated coefficients expected to be $\beta \leq 0$, $>\gamma 0$, and $\theta>0$.

The willing to pay (WTP) calculation is an important part of the study. There are generally three ways to calculate WTP: The first is the so-called WTP average, which is used to calculate the expected value of WTP by numerical integrals in zero to infinite boundary. The second method, known as total WTP average, is used to calculate the expected amount of 
WTP by a numerical integral in the range of $-\infty$ to $+\infty$, and the third method, called WTP average, is the part used in this paper to calculate the expected WTP value by the numerical integral of the Equation (4) in the zero to maximum bid boundary.

$$
\begin{aligned}
& \text { (4) } E(W T P)=\int_{0}^{\infty} f_{\eta}(\Delta U) d A=\int_{0}^{\infty}\left(\frac{1}{1+\exp \left[-\alpha^{*}+\beta A\right]}\right) d A \\
& \text { (5) }\left[\alpha^{*}=(\alpha+\gamma Y+\theta S)\right]
\end{aligned}
$$

Where $E(W T P)$ is the expected value of willingness to pay and $\alpha^{*}$ is a width from the modified origin added by socio-economic parameters to the statement of the width from the initial origin $\alpha$. When the size of visitor's WTP is available, the lake's annual recreational value is obtained. (Ghorbani et al., 2009: 18: 18).

Ultimately, the factors affecting the rate of visitors' willingness to pay for going to Black Twin Lake were estimated by using regression analysis. To do so, the maximum amount declared by the individual as the maximum willingness to pay over a period was fitted as a dependent variable on the economic and social variables based on the regression model of the Equation 6.

$$
\text { (6) } Y_{i}=\alpha+\beta_{1} X_{1}+\beta_{2} X_{2}+\beta_{3} X_{3}+\beta_{4} X_{4}+Z_{i}
$$

Where $\mathrm{Y}$ is the visitor's maximum willingness to pay, $X_{1}$ the education status, $X_{2}$ the income rate, $X_{3}$ the household dimension, and $X_{4}$ the proposed amount, $\mathrm{Z}$ is the other effective factor. The present study considered the error level (d) $5 \%$ of the sample size required by using equation (7), 384 people are obtained.

$$
\text { (7) } n=\frac{z^{2} * p * q}{d^{2}}
$$

Where $\mathrm{n}$ is the sample size, $\mathrm{z}$ the value of the standard normal variable which equals to 1.96 at a $95 \%$ confidence level. $\mathrm{P}$ : is the value of the attribute ratio in the community assumed 0.5. q: The percentage of people who lack the attribute in the community assumed also 0.5. A total of 12 questionnaires were omitted due to a defect in completion step and the output of the Logit model was estimated 372 questionnaires.

\section{3-Introduction to Abdanan Black Twin Lake}

Black Twin Lake is located at $35 \mathrm{~km}$ away from the south of Abdanan city on the southern slope of Kabir Mountain and $180 \mathrm{~km}$ from the south of Ilam city, west to Iran. The lake is one of the rarest natural phenomena in the country and it has always attracted many tourists. It is surrounded by relatively high plains and mountains around the lake and has attractive and spectacular spring and autumn effects. The origin of this lake is depths of the earth and it has beautiful and spectacular resources. This lake is a river type, and its cut-off paths of the gullies are filled with water, so they give rise to crescent-shaped (cow's horns) lakes.

\section{Research findings}

Amongst the respondents, 210 (or 55\%) individuals were male and 174 (or 45\%) individuals were female. 92 (or 24\%) individuals had governmental occupations and 292 (or 
$76 \%$ ) individuals were self-employed. $0.06 \%$ was in the age group of $20-15$ years, $0.36 \%$ in the age group of $30-30$ years, $0.30 \%$ in the age group of $40-40$ years, $0.15 \%$ in the age group of $40-50$ years and $13.1 \%$ Respondents were 50 years old or older. This is indicative of the suitability of the lake for young to middle-aged people

\subsection{Investigating the willingness to pay of lake visitors}

The main questions part of the Twin Lake Recreational Value Questionnaire was devoted to the visitors' WTP, through which three bids of 10000, 20000 and 30000 Rials $(0.07,0.14$ and $0.22 \$$ ) were presented as three interrelated questions. In the first question, the suggested bid price of 20000 Rials $(0.07 \$)$ was questioned and when the positive response was received, the visitors would be suggested higher price (30000 Rials) and when the negative response was received, lower (10000 Rials) would be suggested. Eventually, the visitors' maximum willingness to pay was also asked for further analysis. The findings from visitors' willingness to pay for the recreational value of the Abdanan Black Twin Lake are presented in Tables 1 and 2.

Table 1: Status of Response to Proposed Amount for Recreational Assessment of Abdanan Black Twin Lake

\begin{tabular}{ccccc}
\hline $\begin{array}{c}\text { Status/ price } \\
\text { Rials }\end{array}$ & frequency & First offer & Second offer & Third offer \\
\hline acceptance & Number & 201 & $(10000)$ & $(30000)$ \\
& percentage & 52.34 & 87 & 103 \\
& Number & 183 & 22.65 & 26.82 \\
\hline Rejection & percentage & 47.66 & 96 & 98 \\
& Number & 384 & 183 & 25.52 \\
\hline Total & percentage & 100 & 47.65 & 52.34 \\
\hline
\end{tabular}

Source: Findings from the paper

Table 2: Respondents' Maximum Willingness to Pay for the recreational use of Abdanan Black Twin Lake

\begin{tabular}{cccccccc}
\hline $\begin{array}{c}\text { Maximum } \\
\text { Willingness to Pay } \\
\text { (Rials) }\end{array}$ & 5000 & 10000 & 20000 & 30000 & 40000 & 50000 & 100000 \\
$\begin{array}{c}\text { frequency } \\
\text { percentage }\end{array}$ & 21 & 85 & 94 & 46 & 17 & 30 & 11 \\
\hline
\end{tabular}

Source: Findings from the paper

Overall, findings from the section on visitors' willingness to pay for entrance fee indicated that $304(79 \%)$ of the 384 respondents were willing to pay for recreational use of the Black Twin Lake, and 80 respondents $(21 \%)$ were reluctant to pay. 


\subsection{Interpretation of Logit Model's Coefficients}

Logit model was obtained through using data in 384 questionnaires and the coefficients of explanatory variables of the model were estimated by Eviews software. The results are presented in Table 3.

Table 3: Findings from Estimating the Contingent Valuation Model (Logit) of Abdanan Black Twin Lake

\begin{tabular}{cccc}
\hline variable & coefficient & Statistics Z & P-Value \\
\hline$\alpha$ & -0.103 & -3.17 & 0.0015 \\
\hline$X_{1}$ & 0.084 & 2.93 & 0.0033 \\
$X_{2}$ & 0.005899 & 4.39 & 0.0000 \\
\hline$X_{3}$ & --0.231 & -2.13 & 0.0324 \\
\hline$X_{4}$ & -0.00058 & -8.03 & 0.0000 \\
\hline
\end{tabular}

Diagnostic statistics

$$
\begin{array}{cc}
\text { Prob }(\mathrm{LR} & \mathrm{R}^{2}=0.76 \\
\text { stat })=0.0000 &
\end{array}
$$

Source: Findings from the paper

The findings from Table 6 show that all variables are statistically significant with expected sign. The coefficient of model determination is 0.76 , i.e., the explanatory variables were able to explain $76 \%$ of the dependent variable changes, indicating an acceptable sign (significance of the whole regression). The probability value of the LR statistic implies that the null hypothesis of this statistic confirming the rejected coefficients are not significant and all the coefficients of the model are valid.

(A) The calculated coefficient for the educational status variable $\mathrm{x}_{1}$ is 0.084 . This coefficient is significant at the $5 \%$ level with a positive sign, which means that as the level of education increases, people's willingness to pay for visiting the lake increases. This result is consistent with the results from (Timurenjad et al., 2019) and (Moslemi et al., 2016).

B) The estimated coefficient for the income level variable $\mathrm{X}_{2}$ is 0.005899 . This coefficient is significant at the $5 \%$ level with the positive sign, so as people's income levels increase, their willingness to pay for visiting the lake increases. This result is consistent with the results of (Moslemi et al., 2016) and (Mahdavi et al., 2017).

The estimated coefficient for the household dimension variable $\mathrm{X}_{3} \mathrm{is}-0.223$. This coefficient is significant at the $5 \%$ level with a negative sign, which means that as household size increases, the willingness to pay for visits decreases. This result appears to be due to the increase in household visitation costs due to the increasing number of members. This result is consistent with the results of (Mahdavi et al., 2017) and (Moslemi et al., 2016) and (Timournejad et al., 2019). 
D) The estimated coefficient for the proposed amount variable $\mathrm{X}_{4}$ is -0.00058 . This coefficient is significant at the $5 \%$ level with a negative sign, which means that the amount of willingness to pay will decrease as the proposed amount increases. This result is consistent with the results (Timurenjad et al., 2019) and (Moslemi et al., 2016).

The regression model is then estimated as Equation 8.

$$
Y_{t}=-0 / 1037+0 / 0846 X_{1}{ }^{+6 / 47 e-0 / 07} X_{2}^{-0 / 231} X_{3}{ }^{-0 / 000587} X_{4}
$$

\subsection{Calculating the willingness to pay value}

After estimating the parameters of the Logit model which is the same as the recreational value of the Abadan twin lake, the expected value of willingness to pay is calculated through Equation 9.

$$
E(W T P)=\int_{0}^{\infty} f_{\eta}(\Delta U) d A=\int_{0}^{\infty}\left(\frac{1}{1+\exp (-\{0.135-0.000587 A\})}\right) d A=1299.699
$$

Accordingly, the average respondents' willingness to pay for visiting the Black Twin Lake was calculated at 1299.7 Tomans $(0.09 \$)$ per visitor.

Also, the annual value of the Black Twin Lake was estimated to be 467,000/4692 Tomans (34.59\$). According to the average household size (equivalent to 4 persons), the recreational value per household is estimated at 5460 Tomans $(0.40)$ and the willingness to pay is estimated at 1299.7 Tomans $(0.09 \$)$.

\section{Conclusions and Suggestions}

To estimate Contingent valuation method was used to estimate the recreational value of Abadan Twin Lake. 384 questionnaires were completed. Logit regression model was used to measure WTP and parameters of this model were estimated based on maximum likelihood method. The average willingness to pay of visitors for the recreational value of Abadan Twin Lake for recreational value of this lake was obtained in the sample of 13000 Rials $(0.09 \$)$. According to the family size of 4 people, recreational value for each household was 54600 Rials $(0.40 \$)$ and recreational value of this lake was equal to $4,678,924,670$ Rials $(34658 \$)$ per year.

Based upon obtained findings, it can be supposed that the use of economic tools such as the contingent valuation for environmental protection and lakes can provide a more realistic picture of the economic value of projects and be effective in advancing environmental policies and environmental enhancement. Respondents' income had a significant positive effect on visitors' willingness to pay. Therefore, it is recommended that in order to maintain and enhance this value, the income levels of people through equitable distribution of income be improved. Consequently, the move to increase people's per capita income (economic growth) will increase the number of visits to the Black Twin Lake.

The government should give greater value to public spaces, parks and lakes that are publicly owned and take the necessary measures to protect, improve and develop them. Increasing the cost of preserving lakes and natural resources in the country's general budget and revising the value of these resources in development projects is emphasized to further protect these resources and prevent them from being destroyed. Considering the views of the 
people in this study and the shortcomings and problems of the lake, it is suggested that with proper planning and management, lake problems such as lack of health, welfare and security facilities will be resolved.

Acknowledgements

The authors extend their gratitude to Ilam University.

Authors' contributions

All authors contributed to the drafted the manuscript, revised it critically and approved the final version.

Availability of data and materials

All data generated or analyzed during this study are included in this published article.

Consent to Participate

Participants' consent was obtained Written

Consent for publish

Not applicable.

Ethical approval

Ethical approval was not required for this study.

Funding

There are no benefits in any form have been or will be received from a commercial party related directly or indirectly to the subject of this article.

Competing interests

The authors declare that they have no competing interests.

\section{References}

Abrishami, H. (1999). Principles of econometrics (compiled by Damodar Gujarat). (2), Tehran: Tehran University Press.

Amirnejad, H., \& Rafiei, H. (2009). Economic assessment of environmental satisfaction (Case Study of Abbasabad Forest Tourism Area, Mazandaran Province). Agricultural Sciences and Natural Resources, 16(3), https://www.sid.ir/en/journal/ViewPaper.aspx?id=173393

Timur Nezhad, S. et.al. (1398). Estimation of recreational value of Ilam Park Mellat using conditional valuation method. Journal of Geography (Regional Planning), Ninth Year, (3), pp 625-640. https://www.magiran.com/paper/2030777

Rahali, H, Heydari Chapana, R. \& Khodavardizadeh, M. (1392). Estimating recreational value and investigating factors affecting tourists' willingness to pay for destruction 
mill by using contingent valuation method, Journal of Geography and Planning, (17), no.44, pp 95-117. http://ensani.ir/fa/article/327154/

Rajabi, M. \& Mousavi, N (2014). Estimation of tourism and conservation values of Isfahan's Naghshqahan Square (Application of Contingent Valuation Method). Quarterly Journal of Economics, 8, no 27, pp 127-146. https://www.sid.ir/Fa/Journal/ViewPaper.aspx?ID=251481.

Seyed Salehi, S.A. et.al. (1396). Two-dimensional conditional valuation of an indoor park (Case Study of Shiraz Azadi Park). Journal of Environmental Science and Technology, (19), pp596-585. https://www.magiran.com/paper/1804313

Shabanzadeh, P. et.al. (2014). Economic evaluation of recreational services and determination of visitors' willingness to pay for visiting urban tourism (Case Study: Isfahan Flower Garden). Urban Economics and Management, 4, no. 13, pp 1-19. http://iueam.ir/browse.php?a id=312\&sid=1\&slc lang=fa

Ghorbani, R. (2008). Evaluation of park deficiency in Tabriz urban areas using park per capita and buffering method. Two Quarterly Journals, Seventeenth Year, Ex 47, pp 109-201. https://www.sid.ir/en/journal/ViewPaper.aspx?id=211129

Ghorbani, M; and Firouz Zare, A. (2008). Introduction to environmental valuation. Ferdowsi University Press. (503), pp 12-23, https://igrd.um.ac.ir/article/view/36429/10272.

Karami, O. et.al. (1395). Estimation of amusement forest park recreational value using contingent valuation method, Environmental Research, 7, no. 31, pp 85-92. https://www.agriculturejournals.cz/web/jfs.htm?type=article\&id=95 2019-JFS

Moslem, A. et.al. (2016). Estimating the recreational value of tourism areas (Case Study: Rudbar Qasran), Quarterly Journal of Tourism Management Studies, Eleventh Year, Ex 35, pp1-18. https://www.sid.ir/en/journal/ViewPaper.aspx?id=551493

Mousavi, N (1394). Estimation of the economic valuation of the waterfall and recreational area of Khafar and determining the factors affecting the willingness to pay using the conditional valuation method. The fifth planning quarterly, (1), pp157-170. https://www.sid.ir/en/journal/ViewPaper.aspx?id=460321

Mahdavi, A. et.al. (1396). Estimation of Amusement Value of Chagasabz Ilam Forest Park by Contingent Valuation Method, Journal of Forestry and Wood Products, Ex 2, pp250241. https://www.sid.ir/Fa/Journal/ViewPaper.aspx?ID=310169

Yavari, Gh; and Asadi Bazarde, L. (2016). Comparison of contingent valuation methods and travel costs in estimation of Yazd mountain park amusement value. Economic Progress Policy Making 4, pp 126_92. http://ensani.ir/fa/article/380861/

Asafu-Adjaye, J. (2005). Environmental Economics for Non-Economists. Techniques and Policies for Sustainable Development, 2nd ed. World Scientific Publishing Co, Singapore, pp1-377. https://www.amazon.com/Environmental-Economics-NonEconomists-Sustainable-Development/dp/9812561234

- Halkos, G. \& Matsiori, S. (2014). Exploring social attitudes and willingness to pay for water resources conservation. Journal of Behavioral and Experimental Economics, 
49, pp54-62.

DOI: $10.1016 /$ j.socec.2014.02.006,https://www.researchgate.net/publication/262880595 Exploring social attitude and willingness to pay for water resources conservation

Jianjun, J., Chong, J., \& Lun, L. (2013). The economic valuation of cultivated land protection. A contingent valuation study in Wenling City, China. Landscape and Urban Planning, 119, pp158-164.

Marta-Pedroso, C. et.al. (2007). Testing for the survey mode effect on contingent data quality evaluation. A case of web based versus in-person interviews. Ecological Economics, 62 (3-4), pp388-398. DOI: 10.1016/j.ecolecon.2007.02.005, https://www.researchgate.net/publication/222562249 Testing for the survey mode effe ct on contingent valuation data quality $A$ case study of web based versus inperson interviews

Nandagiri, L. (2015). Evaluation of economic value of lake pills using travel cost and contingent valuation methods. Aquatic Procedia, 4, pp1315-1321. https://cyberleninka.org/article/n/1067832

Park, T. \& Loomis, J. (1996). Joint estimation of contingent valuation survey responses. Environmental and Resource Economics, 7 (2), pp149-162. https://ideas.repec.org/a/kap/enreec/v7y1996i2p149-162.html

Rathnayake, R. M. W. (2016). Pricing the enjoyment of 'elephant watching'at the Minneriya National Park in Sri Lanka. An analysis using CVM. Tourism Management Perspectives, 18, pp26-33. https://daneshyari.com/article/preview/1013580.pdf

Voke, M, Fairley, I. Willis, M. \& Masters, I. (2013). Economic evaluation of the recreational value of the coastal environment in a marine renewables employment area. Ocean \& Coastal Management, 78, pp77-87. 